Acta Hispanica (2018) 23: 69-84

\title{
DE LA DICTADURA MODERNIZANTE HASTA LA POSDEMOCRACÍA HÍBRIDA. LOS CAMBIOS POLÍTICOS Y ECONÓMICOS EN BRASIL (1964-1985)
}

\author{
ISTVÁN SZILÁGYI
}

Universidad de Pécs

\begin{abstract}
Resumen: Durante los últimos setenta años en el continente latinoamericano se agudizaron las contradicciones de la crisis estructural de la economía, de la política y de la sociedad. Se presentaron las distintas estrategias y tentativas para superar la crisis estructural del hemisferio. Una de estas respuestas fue la intervención militar de las fuerzas armadas latinoamericanas. Con la intervención del Ejército brasileño de 1 de abril de 1964 en el continente comenzó la época del nuevo golpismo. Las dictaduras y los regímenes militares de nuevos tipos establecieron los estados de excepción y los sistemas políticos autoritarios e iniciaron la refundación y la reorganización total de las estructuras económicas, sociales y políticas. A finales de la década de los años ochenta fueron derrocadas las dictaduras militares y comenzó una nueva etapa en la historia de América Latina. En Brasil fracasó el régimen militar en marzo de 1985, fue introducido y restablecido el sistema democrático y comenzó la nueva época del cambio. El país se mudó y se modernizó. A pesar de las transformaciones y cambios mencionados, permanecieron los históricos enclaves autoritarios y heredados en el sistema político brasileño y no disminuyeron las desigualdades económicas y sociales tampoco. El ensayo analiza las transformaciones, los cambios políticos, económicos y los procesos llevados a cabo en Brasil durante la época de la dictadura.
\end{abstract}

Palabras claves: nuevo militarismo, estado de excepción, modelos de modernización, América del Sur, estrategias alternativas, cambios geopolíticos

\begin{abstract}
In South-America over the past seventy years the contradictions of economic, social and political structures have been deepening. In order to surmount the structural crisis the different political forces and governments have elaborated various strategies. One of the replies to the crisis was given by the Latin-American Military Forces. The takeover committed by the Brazilian Army on 1 April,1964 meant the beginning of a new militarism. The new types of military dictatorship created excepcional states and started the total reorganization and modernization of the societies -economic, political and ideological- territories. The break-down of the military dictatorships in South-America took place in the 1980s and 1990s and it was to say that a new era started in the history of Latin-America. In Brasil the military system lost his power in March,1985 and the democratic system was intended to be restored,which meant a new period in the history of that country. Brasil has changed and has been modernized, however the enclaves of historical heritage with the great influence have not disappeared and the economic and social inequalities have not essentially decreased yet. The study aims at analizing the economic and political changes during the period of dictatorship in Brasil.
\end{abstract}


De la dictadura modernizante hasta la posdemocracía híbrida. Los cambios políticos y económicos en Brasil (1964-1985)

Keywords: new militarism, exceptional state, models of modernization, South America, alternative strategies, geopolitical changes

\section{Introducción}

Durante los últimos setenta años en el continente latinoamericano se agudizaron las contradicciones de la crisis estructural de la economía, de la política y de la sociedad. Se presentaron las distintas estrategias y tentativas para superar la crisis estructural del hemisferio. Una de estas respuestas fue la intervención militar de las fuerzas armadas latinoamericanas. Con la intervención del Ejército brasileño de 1 de abril de 1964 en el continente comenzó la época del nuevo golpismo. Las dictaduras y los regímenes militares de nuevos tipos establecieron los estados de excepción y los sistemas políticos autoritarios e iniciaron la refundación y la reorganización total de las estructuras económicas, sociales y políticas. A finales de la década de los años ochenta fueron derrocadas las dictaduras militares y comenzó una nueva etapa en la historia de América Latina. En Brasil fracasó el régimen militar en marzo de 1985, fue introducido y restablecido el sistema democrático y comenzó la nueva época del cambio. El país se mudó y se modernizó. A pesar de las transformaciones y cambios mencionados, permanecieron los enclaves autoritarios heredados históricos en el sistema político brasileño, no desaparecieron las fronteras entre los ricos y pobres y no disminuyeron las desigualdades económicas y sociales tampoco. El ensayo analiza las transformaciones, los cambios políticos, económicos y los procesos llevados a cabo en Brasil durante la época de la dictadura.

\section{Los antecedentes y las características de la dictadura brasileña}

O golpe de Estado de 1964 é o evento-chave da história do Brasil recente. Dificilmente se compreenderá o país de hoje sem que se perceba o verdadeiro alcance daquele momento decisivo. Ele inaugurou um regime militar que duraria 21 anos [...] Foram no poucos os que apoiaram o golpe: a imprensa, a Igreja Católica,amplos sectores da classe média urbana.Instituções que, anos depois,se tornariam fortes opositores do regime - como Ordem dos Advogados do Brasil, a Associação Brasileira de Imprensa,ou a Conferência Nacional dos Bispos do Brasil (Fico, 2014:1). 
El 1 de abril de 1964 fue introducida en Brasil una dictadura civil-militar que representó el tipo de estado de excepción y al mismo tiempo representó el modelo de modernización conservadora-bismarckiana. ${ }^{1}$

Se plantea la cuestión: ¿Fue verdaderamente el gobierno militar un régimen modernizante? ¿Contribuyó a la inserción del país la economía mundial? ¿Contribuyó para ajustarse al sistema económico mundial y para atenerse al centro económico mundial? ¿El intento de la refundación y de la reorganización total del país promovió el desarrollo económico y facilitó la modernización de la estructura política de Brasil?

En 2014 fue el cincuenta aniversario del golpe de estado brasileño y por esta ocasión nacieron muchos libros, publicaciones y trabajos ${ }^{2}$ sobre los acontecimientos de cincuenta años atrás. El aniversario provocó muchos debates científicos y políticos sobre las cuestiones mencionadas también. Marcos Napolitano llama la atención sobre las siguientes circunstancias:

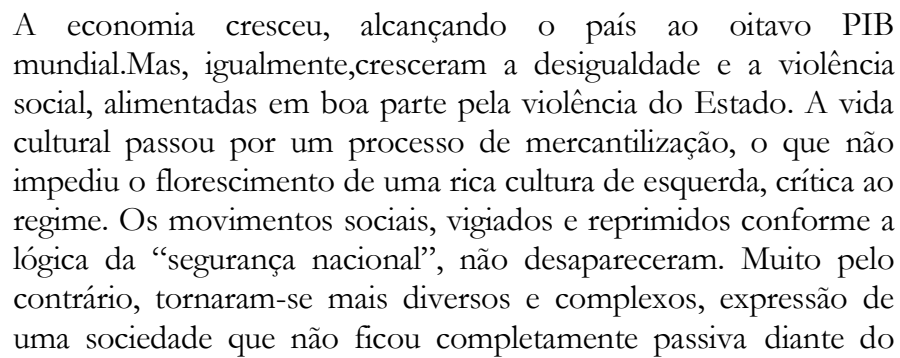

${ }^{1}$ Sobre el tema véase más detalladamente István, Szilágyi. 2015. "El nuevo golpismo y el proceso de modernización en América Latina: el caso chileno" Atas do XI Colóquio Internacional Tradição e Modernidade no Mundo. Rio de Janeiro, 24-26 de novembro 2015. Universidade do Estado de Rio de Janeiro. Asequible en:

http://coloquioiberoamerica.wix.com/2015.; István, Szilágyi. 2016. "Models and challenge of Modernization and regional integrations in Latin America" Rusia e Iberoamérica en el mundo globalizante, II. San Petersburgo: Universidad Estatal de San Petersburgo. 273-291.; István, Szilágyi. 2017. "Modelos de modernización,integraciones regionales nuevas, estrategias alternativas y los cambios geopolíticos en América Latina" A Integração Sul-Americana e a Inserção das Regiōes Periféricas. Natal. 543-568. Asequible en: http://www.cchla.ufrn.br/iicongeo/ANAIS-2-CONGEO-EIXO-TEMATICO-3.pdf 2 Véase, por ejemplo, Aarão Reis, Daniel. 2014. Ditadura e democracia no Brasil. Rio de Janeiro: Jorge Zahar Editor Ltda.; Fico, Carlos. 2014. O golpe de 1964. Rio de Janeiro: Editora FGV.; Reid, Michel. 2016. Brasil A esperança e a deceşão. Lisboa: Editorial Presença. 
De la dictadura modernizante hasta la posdemocracía híbrida. Los cambios políticos y económicos en Brasil (1964-1985)

autoritarismo. O golpe foi puramente militar ou civil-militar? A ditadura para valer só começou com o AI-5, em 1968? A esquerda armada foi a principal responsável pelo acirramento da violência de Estado? As artes e a cultura de esquerda estavam inseridas na indústria cultural ou foram meras concessões episódicas por parte desta? A sociedade, predominantemente, resistiu ou apoiou a ditadura? A abertura do regime foi um movimento consciente dos militares, que preparavam a sua saída do poder sem hesitações? Defendo a interpretação de que[...] O golpe foi o resultado de uma profunda divisão na sociedade brasileira, marcada pelo embate de projetos distintos de país, os quais faziam leituras diferenciadas do que deveria ser o processo de modernização e de reformas sociais. O quadro geral da Guerra Fria, obviamente, deu sentido e incrementou os conflitos internos da sociedade brasileira, alimentando velhas posições conservadoras com novas bandeiras do anticomunismo. Desde 1947, boa parte das elites militares e civiles no Brasil estava alinhada ao mundo "cristão e Ocidental" liderado pelos Estados Unidos contra a suposta "expansão soviética" (Napolitano, 2014:1-2).

Es decir, a partir de marzo de 1947, cuando el presidente norteamericano, Harry Truman declaró la nueva estrategia de los EE. UU., manifestando la política de la contención del comunismo, en la vida de los países latinoamericanos ya prevalecieron las líneas generales de la Doctrina de Seguridad Nacional (DSN), y en el caso de Brasil, la doctrina ya era propagada y elaborada por la Escuela Superior de Guerra. Y como ya hemos mencionado, una importante parte de las élites militares y civiles brasileñas ya fue empeñada y obligada al mundo cristiano y occidental, liderado por los Estados Unidos contra la expansión soviética supuesta.

A partir de la Revolución Cubana, en 1959, América Latina fue uno de los territorios privilegiados de la Guerra Fría, en donde pasó a primer plano la lucha contra el enemigo interno y la subversión comunista. Esta fue la época de la crisis de misiles en Cuba y el comienzo de la guerra de Vietnam también. En estas circunstancias fue establecida la dictadura civil-militar en Brasil.

Mientras tanto el gobierno de João Goulart, (Jango), comenzó a introducir las reformas básicas - voto para los analfabetos, reforma agraria, nacionalización de la economía, reforma urbana, reforma bancaria, reforma electoral, reforma universitaria, la legalización del Partido Comunista Brasileño, etc.- pero las fuerzas opositoras las bloquearon. Las reformas de Jango fracasaron y la crisis 
económica y política fue seguida por el golpe de estado del nuevo militarismo. Todas las fuerzas opositoras acentuaron la necesidad de un contragolpe preventivo, de una "revolución redentora." Los análisis tratan de la intervención indirecta de los Estados Unidos -operación Brother Sam- también. Lo que es cierto que la causa fundamental de la victoria de la dictadura militar fue la crisis económica y política del gobierno de Goulart.

Jango (João Goulart) era el vicepresidente de Jânio Quadros en las elecciones presidenciales de 30 de octubre de 1960. Ellos obtuvieron la mayoría $-5,6$ millones- de votos. El problema comenzó, cuando el 25 de agosto de 1961 el presidente Quadros inesperadamente dimitió. De resultas de los muchos compromisos Jango fue elegido presidente por el Congreso Nacional y el 7 de septiembre, en el día de la independencia de Brasil fue investido solemnemente. Al mismo tiempo, El Congreso Nacional modificó la Constitución, disminuyendo las facultades y competencias del presidente e introdujo el sistema de parlamentarismo. Goulart no quería aceptar esta situación y convocó un plebiscito. Y como resultado de la consulta popular de 6 de enero de 1963 retornó el sistema del presidencialismo. ${ }^{3}$

Mientras tanto Jango comenzaba a introducir las reformas básicas ya mencionadas en diciembre de 1962 con la dirección del famoso economista cepaliano, Celso Furtado fue elaborado el Plano Trienal. El Proyecto contenía los principales elementos de las reformas básicas. Pero por motivo de la resistencia del Congreso Nacional, el Plano fracasó después de cuatro meses. Y al fracaso del plano económico y político siguió el golpe de estado.

¿Qual a importância do governo João Goulart para a história
do Brasil? [...] não por defeitos do governo que exercia, mas,
ao contrário, em razão das qual idades dele. No momento em
que as esquerdas ameaçaram transformar sua agenda refor-
mista em um projeto político de governo, o que aconteceu a
partir do final de 1963, as direitas agiram. O ambiente político
e o tipo de questões que estava em jogo [...] conchavos à
brasileira para superar a crise. Não porque os atores radicali-
zaram suas posições, mas por serem inconciliáveis os valores
e planos estratégicos que informavam as agendas políticas, à
esquerda e à direita. O que se seguiu ao golpe civil-militar das

${ }^{3}$ Más de 11 millones de votantes participaron en el plebiscito y 9457448 votaron a favor del presidencialismo. 
De la dictadura modernizante hasta la posdemocracía híbrida. Los cambios políticos y económicos en Brasil (1964-1985)

direitas contra a agenda reformista foi a afirmação de outro modelo político e ideológico de sociedade e de Estado, esboçado bem antes do golpe: a modernização socioeconômica do país e a construção no longo prazo de uma democracia plebiscitária, tutelada pelos militares, em nome do «partido da ordem» (Napolitano, 2014:10).

\section{Estado de excepción en Brasil}

\subsection{La toma del poder y la construcción del estado de excepción}

El 31 de marzo de 1964 las tropas del ejército brasileño tomaron el poder y derribaron el gobierno de João Goulart. El presidente se refugió en Uruguay. Por este medio comenzó en América Latina la época de la intervención de los ejércitos profesionalizados.

En Río de Janeiro por corto tiempo asumieron el poder los tres miembros del Comando Supremo da Revolução ${ }^{4}$, que en nombre de la Revolución de 31 de marzo de 1964, el 2 de abril designaron como presidente provisional sin poder efectivo a Raniero Mazilli, el presidente del Congreso de los Diputados. Siete días después fue promulgado el Acto Institucional n. ${ }^{\circ} 1$ (AI-1), que ordenó sobre la elección indirecta del presidente el 11 de abril, con la colaboración del Congreso Nacional. El día mencionado los diputados eligieron presidente al general Humberto de Alencar Castello Branco, el Jefe del Estado Mayor. El mariscal entró en su oficio el 15 de abril y hasta 15 de abril de 1967 ejerció su función y así comenzó el primer periodo de la dictadura militar, o sea, el estado de excepción brasileño. Subiendo al poder de mariscal, en Brasil comenzaba el dominio del ejército basado en las actas institucionales que fue legalizado y legitimizado por el Congreso Nacional, que aquel entonces todavía no estaba cerrado y por los trece partidos políticos formalmente existentes. Pero el derecho de la promulgación de los actos institucionales correspondía al presidente. Con la norma jurídica mencionada el Jefe del Estado podía regir y reglamentar todos los aspectos y ámbitos del funcionamiento del estado sin ningún control interno y externo.

${ }^{4}$ Los miembros del Comando Supremo da Revolução fueron Arturo da Costa e Silva, Francisco de Assis Correia de Mello y Augusto Hamann Rademaker Grunewald. 
István Szilágyi

Durante los veintiún años de la dictadura militar aprobaron 17 actos institucionales y 104 reglamentaciones complementarios. La aprobación de los actos institucionales continuó después de la Constitución aprobada el 15 marzo de 1967 por el gobierno militar también.

El Acto Institucional n. ${ }^{\circ} 1$ fue promulgado el 9 de abril de 1964 . Consistía de once artículos. La norma otorgaba al gobierno militar los poderes constitucionales. Abolió el mandato de la legislación. Suspendió diez años el ejercicio de los derechos políticos, seis meses la vigencia de la Constitución y las garantías de los derechos constitucionales. Excluyó de la vida política a 102 políticos de oposición, según una lista que enumeró sus nombres. Introdujo la elección indirecta del presidente con la colaboración del Congreso Nacional, despojado de sus facultades.

El Acto hizo una tentativa para justificar teóricamente la intervención militar y la creación de la base de legitimidad de la dictadura. La toma del poder de las fuerzas armadas llamó a la revolución nacional, que expresaba los intereses y la voluntad del país y la cual era un paso inevitable para salvar y salvaguardar el futuro de Brasil.

É indispensável fixar o conceito do movimento civil e militar que acaba de abrir ao Brasil uma nova perspectiva sobre o seu futuro. podemos leer el documento- $\mathrm{O}$ que houve e continuará a haver neste momento, não só no espírito e no comportamento das classes armadas, como na opinião pública nacional, é uma autêntica revolução. A revolução se distingue de outros movimentos armados pelo fato de que nela se traduz, não o interesse e a vontade de um grupo, mas o interesse e a vontade da Nação. A revolução vitoriosa se investe no exercício do Poder Constituinte. Este se manifesta pela eleição popular ou pela revolução. Esta é a forma mais expressiva e mais radical do Poder Constituinte. Assim, a revolução vitoriosa, como Poder Constituinte, se legitima por si mesma. Ela destitui o governo anterior e tem a capacidade de constituir o novo governo. Nela se contém a força normativa, inerente ao Poder Constituinte. Ela edita normas jurídicas sem que nisto seja limitada pela normatividade anterior à sua vitória. Os Chefes da revolução vitoriosa, graças à ação das Forças Armadas e ao apoio inequívoco da Nação, representam o Povo e em seu nome exercem o Poder Constituinte, de que o Povo é o único titular [...] A revolução vitoriosa necessita de se institucionalizar e se apressa pela sua institucionalização a limitar os plenos poderes de que efetivamente dispõe [...] Para demonstrar que não 
De la dictadura modernizante hasta la posdemocracía híbrida. Los cambios políticos y económicos en Brasil (1964-1985)

\begin{abstract}
pretendemos radicalizar o processo revolucionário, decidimos manter a Constituição de 1946, limitando-nos a modificá-la, apenas, na parte relativa aos poderes do Presidente da República, a fim de que este possa cumprir a missão de restaurar no Brasil a ordem econômica e financeira e tomar as urgentes medidas destinadas a drenar o bolsão comunista, cuja purulência já se havia infiltrado não só na cúpula do governo como nas suas dependências administrativas [...] Fica, assim, bem claro que a revolução não procura legitimar-se através do Congresso. Este é que recebe deste Ato Institucional, resultante do exercício do Poder Constituinte, inerente a todas as revoluções, a sua legitimação $[\ldots]$ Em nome da revolução vitoriosa, e no intuito de consolidar a sua vitória, de maneira a assegurar a realização dos seus objetivos e garantir ao País um governo capaz de atender aos anseios do povo brasileiro, o Comando Supremo da Revolução, representado pelos Comandantes-em-Chefe do Exército, da Marinha e da Aeronáutica resolve editar o seguinte. ${ }^{5}$
\end{abstract}

El Acto Institucional n. 2 (AI-2) fue promulgado el 27 de octubre de 1965. El Acto suspendió la vigencia de la Constitución de 1946 diciendo que la Ley Fundamental es incompatible con el nuevo sistema revolucionario. Por eso declaró la prohibición del funcionamiento de todos los partidos políticos. Al mismo tiempo introdujo el sistema de bipartidismo controlado. Se creó la Aliança Renovadora Nacional (ARENA) que apoyó la dictadura y el Movimento Democrático Brasileiro (MDB) que fue la oposición legal y oficial de la dictadura. Puso bajo el control del poder ejecutivo la organización del juzgado también. Introdujo el poder legislativo del presidente y modificó las reglas de las elecciones indirectas del presidente que según el Acto Institucional n. ${ }^{\circ} 2$ tiene facultades para declarar el sitio de emergencia durante 180 días, sin previas consultas con el Congreso. El presidente pudo intervenir en los asuntos internos de los estados federales también. Antes, los derechos mencionados formaron parte de la competencia exclusiva de los estados federales. El Acto Institucional autorizó al Jefe del Estado para reemplazar los funcionarios de servicios públicos y reglamentar las cuestiones de la seguridad nacional con los decretos presidenciales.

Esta competencia pudo ejercerse después de la consulta con el Consejo de Seguridad Nacional. El Acto Institucional n. 2 se hallaba en vigor hasta la aprobación y la promulgación de la Constitución de 1967. La Constitución fue

${ }^{5}$ http://pt.wikipedia.org/wiki/Ato_Institucional_N\%C3\%BAmero_Um 
aprobada el 24 de enero de 1967 por el Congreso Nacional y entró en vigor el 15 de marzo del mismo año. En la elaboración de la Ley Fundamental formalmente jugaba el papel principal el Congreso Nacional lo que se manifestó a la Assamblea Constituyente, mientras que se excluyeron los diputados de la oposición. Con la aprobación de la nueva Constitución el objetivo del sistema militar fue la legitimación y la consolidación jurídica de la revolución de 31 de marzo de 1964. En la nueva Constitución se incluyeron los actos institucionales y los reglamentos complementarios también.

La Constitución del 15 de marzo de 1967 sucedió a la Constitución Republicana de 1946. La sexta Constitución del país estaba dividida en cinco partes. Contenía trece capítulos y 189 artículos. Su característica principal era que aumentaba la influencia y el rol de poder ejecutivo en contra de la legislación y el juzgado. Esto significó que la mayor parte de las decisiones se concentró en las manos del poder ejecutivo. La Constitución autorizó al poder ejecutivo con la competencia legislativa en las cuestiones de seguridad y de presupuesto. Introdujo la elección indirecta presidencial. El mandato del Jefe del Estado aumentó a cinco años. Frente al federalismo prefirió las tendencias centralizadoras. En el caso de la seguridad nacional introdujo la pena de muerte. Restringió los derechos de los trabajadores y el derecho a huelga. Promulgó la competencia de los tribunales militares en los casos civiles también. Construyó la posibilidad de derogación posterior de las leyes a través de los decretos. ${ }^{6}$

La Constitución no creó una norma estable y persistente. El Acto Institucional n. 5 de 1968 y los demás reglamentos la modifiaron. Durante los veinticinco años fue modificada veintiséis veces.

El primer gobierno militar, comandado por el general Castello Branco, tenía dos objetivos principales: estabilizar la economía y establecer, desarrollar el sistema institucional del régimen. Por eso fue marcado por una política de control de la inflación, la reorganización institucional del sistema económico y político de Brasil. Sus prioridades eran estructurales. El gobierno hubiera querido remover el desarrollo económico, transformar y cambiar radicalmente el sistema político del país. En el terreno económico el objeto principal era preparar y establecer las condiciones del crecimiento del periodo próximo.

\footnotetext{
${ }^{6}$ Véase el texto de la Constitución en el enlace siguiente: http://www.planalto.gov.br/ccivil_03/constituicao/constitui\% \%3\%A7ao67.htm
} 
De la dictadura modernizante hasta la posdemocracía híbrida. Los cambios políticos y económicos en Brasil (1964-1985)

El gobierno de Castello Branco era intervencionista, aplicaba los métodos keynesianos y en parte continuó la política económica reformista del periodo de Juscelino Kubitschek. Su ministro de economía era Delfim Netto, que representaba una práctica mezclada entre el liberalismo económico y la intervención keynesiana. Como escribía Paul Singer:

\begin{abstract}
Mas os governos militares não abandonaram o desenvolvimentismo, ao contrario do que fizeram,mais tarde, seus congêneres na Argentina o no Chile. $O$ golpe militar ocurreu no Brasil num momento em que a hegemonia do keynesianismo na teoria econômica ortodoxa não fora abalada. O papel ativo do Estado na economia para promover o desenvolvimento industrial ainda era aceito.Só muito mais tarde,nos anos 1980, é que viria a ofensiva neoliberal [...] Até o seu fim, em 1985, a economia continuou sob o comando de Antonio Delfim Nettó, um notório desenvolvimentista, partidario do planejamento e próxima do keynesienismo (Singer, 2014:186).
\end{abstract}

Fue el gobierno de Castello Branco que creó el Instituto Nacional de Previdência, el Banco Nacional y en agosto de 1964 aprobó el Plano de Ação Económica do Governo.

El rumbo de la política económica brasileña mudó durante las presidencias de Arturo Costa e Silva (15 de marzo de 1967 - agosto de 1969) y de Emílio Garrastazu Médici (30 de octubre de 1969 - 15 de marzo de 1974). Aquel periodo se llamó políticamente "los años de plomo (chumbo)" y económicamente en aquel entonces comenzó el milagro económico brasileño. Estas dos cosas ejercieron la mayor influencia en la historia de la dictadura militar y mudaron a Brasil.

\title{
3.2. Los Anos de Chumbo
}

En la historiografía brasileña el periodo de seis años comprendido entre 1968 y 1975 se llama Anos de Chumbo (Años de Plomo). Esta fue la etapa más dura de la dictadura. Se inició con la promulgación del Acto Institucional n. ${ }^{\circ} 5$ de 13 de diciembre de 1968 y duró hasta el fin de la presidencia del general Médici. Muchos autores sostienen y consideran que la victoria de la línea dura y la promulgación del Acto Institucional n. ${ }^{\circ} 5$ significó un golpe dentro del golpe. 
Para entonces se desarrolló el mecanismo dictatorial del estado. Se consolidó el sistema político de la dictadura y se institucionalizaron las represiones y la abolición, la liquidación de los derechos políticos y civiles, la restricción del derecho electoral, la prohibición de los partidos políticos. En este periodo llegó a ser formal el funcionamiento del Congreso Nacional, y en aquel entonces introdujeron el poder presidencial sin límites, aprobaron la Ley de Seguridad Nacional y ampliaron los poderes y competencias de Serviço Nacional de Informações (SNI), creado el 13 de junio de 1964.

La norma jurídica más importante del periodo fue el Acto Institucional n. 5 de 13 de diciembre de 1968. El Acto autorizó con los poderes extraordinarios al presidente. El Jefe del Estado tuvo el derecho de disolución del Congreso Nacional, de destitución y de reemplazo de los funcionarios públicos, de anulación de los mandatos de los diputados, de suspensión de diez años de los derechos políticos de cualquier ciudadano, de proclamación del estado de sitio, de entrega a los tribunales militares a los crímenes políticos. El Acto prohibió las manifestaciones políticas y en el caso de las crímenes políticos y crímenes cometidos contra la seguridad nacional derogó el principio de babeas corpus.

Después del restablecimiento del orden, el presidente Arturo Costa e Silva planteó encaminar una suave liberalización del estado de excepción, pero el 28 de agosto de 1969 sufrió una hemorragia cerebral. Por eso el 31 de agosto se formó una Junta Governativa Provisoria de tres miembos ${ }^{8}$ que con el apoyo de las fuerzas armadas promulgó el Acto Institucional n. ${ }^{\circ} 12$ sobre el poder ejecutivo y el 17 de octubre promulgó el primer addenda de la Constitución de 1967.

El estado provisorio terminó con el Acto Institucional n. ${ }^{\circ} 16$ de 14 de octubre de 1969, el cual declaraba vacantes los puestos de presidente y de vicepresidente y ordenaba elecciones presidenciales. El ejército apoyó la candidatura del general Emílio Garrastazu Médici, el Jefe del Estado Mayor, y le propuso al Congreso Nacional. Médici obtuvo la mayoría de los votos y el 25 de octubre de 1969 llegó a ser el presidente de Brasil, puesto que ocupó hasta el 15 de marzo de 1974.

\footnotetext{
7 http:/ /www.planalto.gov.br/ccivil_03/ait/ait-01-64.htm.

${ }^{8}$ Los miembros de la Junta Gobernativa fueron Aurelio de Lira Tavares (Ejército), Augusto Hamann Rademaker Grünewald (Marina) y Márcio de Sousa e Melo (Fuerza Aérea).
} 
De la dictadura modernizante hasta la posdemocracía híbrida. Los cambios políticos y económicos en Brasil (1964-1985)

\subsection{El milagro económico y la modernización}

Los duros embates de la vida durante los años de chumbo se enlazaron con la política económica introducida por el régimen. En interés de superar la crisis estructural y la inserción del país a la economía mundial, para atenerse al centro económico mundial, en pro de la modernización del país y los esfuerzos de llegar a ser un gran poder o un poder emergente, los señores del régimen decidieron introducir el proceso de acumulación forzosa del capital y de reorganización total de la sociedad y de la economía brasileña.

El estado política y económicamente fuerte formó parte inseparable de la política económica de los nuevos tipos de dictaduras latinoamericanas y contribuyó considerablemente a los milagos económicos provisionales. Pero el caso brasileño se diferenció de otros regímenes militares porque durante la época de la dictadura militar los distintos gobiernos autoritarios aplicaron la política económica desarrollista, o sea, en parte continuaron y siguieron los esfuerzos y programas de los regímenes civiles, anteriores a la dictadura. Esta política económica se llamaba la sustitución de importaciones. La estrategia escogida expresaba las aspiraciones de los líderes del régimen que querían convertir a Brasil en una gran potencia y aflojar los lazos con los Estados Unidos también.

Como hemos dicho, el milagro económico brasileño coincidió con la política represiva y totalitaria de los anos de chumbo, y esto significaba para los sectores trabajadores el aumento de la desigualdad social y la pobreza -en algunos casos la miseria - y para los ricos la concentración de la renta. El mismo presidente Médici reconoció que o Brasil vai bem, mas o povo vai mal.

A pesar de esto la propaganda oficial del Estado acentuó que nunca fomos tão felices. En la época del milagro económico brasileño, en 1970, llegó a ser el tricampeón mundial de la selección nacional de fútbol. Todos estos efectos y circunstancias contribuyeron al desenvolvimiento del orgullo brasileño, al aumento de la legitimidad internacional del país. Así nació el tercer lema de la propaganda y de la comunicación gubernamental: Brasil, ame-o ou deixe-o.

Pero la liquidación de la cantidad de problemas históricos no prometía una solución rápida y fácil. Por eso el gobierno militar, ya en abril de 1964, elaboró el Programa de Ação Econômica do Governo (PAEG), el cual estaba marcado por la condición necesaria de poner en marcha el desarrollo económico, la lucha 
contra la inflación y la ejecución de las reformas estructurales. El gobierno intentó concentrar el desarrollo del fundamento, de la base de la industria (metalúrgica, siderúrgica, sector energético y química petrolera, etc.), el aumento del consumo interno, la disminución de la importación, el crecimiento de la exportación y la transformación del sistema financiero. Este planteamiento se efectuó en 1968. Como consecuencia de esto en 1968-1969 comenzó la época del crecimiento y del milagro económico.

Entre 1969 y 1973 el GDP brasileño alcanzó un 10\% de desarrollo. La rata de inflación oscilaba entre 15-20\%. Aumentaron con 15\% las inversiones y construcciones estatales. La prioridad de la política económica fue el desarrollo de las infraestructuras. Y como resultado de esto nacieron muchas nuevas ramas industriales. Aumentó la actividad económica y se aceleró el crecimiento de la economía. Al seguir el concepto keynesiano de Delfim Netto, el estado invirtió gran parte del capital. Según el ministro de Economía, el crecimiento hubiera sido irrealizable sin aumento de poder adqusitivo del mercado interno. La recesión económica se superó con la inversión de capital extranjero, con la regulación estatal y con el apoyo financiero de las empresas nacionales. Por eso el estado tuvo que invertir y apoyar tales ramas industriales nacionales, como la industria pesada, la siderurgia, la petroquímica, la construcción naval y la energía hidráulica. A consecuencia de esto entre 1968 y 1973 creció con 23\% del consumo de los productos durables y con el 18,1\% la inversión de capital. Y como consecuencia de estos efectos y factores, así como de las medidas represiales y la privación de los derechos de los empleados, el mantenimiento del bajo nivel de los salarios de trabajo (arrocho salarial), junto a las compañías transnacionales se fortalecieron las empresas nacionales -Petrobras, Vale do Rio Doce, Telebrás- también.

El milagro económico brasileño sellado con el nombre de Delfim Netto según el punto de vista teórico muestra una gran similitud y proximidad con el modelo bismarckiano-latino, con la modernización conservadora elaborada por el Barrington Moore Junior, con la política económica aplicada en la Unión Soviética durante los años treinta y con los países de Europa Central y Oriental en las décadas de 1950 y 1960, lo que simbolizó la modernización de easternización ${ }^{9}$, así como el concepto neoliberal/neoconservador de la Escuela de Chicago,

\footnotetext{
${ }^{9}$ Modernización de tipo oriental.
} 
De la dictadura modernizante hasta la posdemocracía híbrida. Los cambios políticos y económicos en Brasil (1964-1985)

liderado por Milton Friedman ${ }^{10}$ y con las tradiciones keynesianas. La política económica de la dictadura brasileña se puede considerar una mezcla especial y particular de las políticas económicas enumeradas y mencionadas.

La mayor parte de los analistas brasileños acepta el concepto de la modernización conservadora $^{11}$, en la cual la tentativa de la inserción al sistema económico mundial, el aceleramiento del desarrollo y la liquidación de la dependencia económica se consideran como una revolución dirigida por el ejército desde arriba, y en la cual prevaleció y funcionó la alianza entre la oligarquía agraria, la burguesía nacional relativamente débil y las empresas transnacionales.

Pero una parte de la inversiones sirvió para los aspectos prestigiosos y para la creación de las condiciones de convertirse en gran poder. Es decir la época de 1968 y 1974 fue el periodo de la demostración y de los esfuerzos de un estado de gran poder también. Junto con el desarrollo de las infraestructuras, del transporte, del sector energético, militar, de la prensa y de la actividad editorial, llegaron las inversiones de tipo faraónico (Obras Faraônicas) también. Éstas tenían pocos beneficios, pero conllevaban ganancias de propaganda. Éstos fueron, por ejemplo, la central hidroeléctrica de Itaipu, el puente de Niterói, de 13,9 kilometros de largo, etc. Más tarde los juicios cambiaron.

En el periodo del milagro económico se inició el programa nuclear brasileño y el proceso de desarrollo de la integración de las regiones norteñas también. El crecimiento económico y la estabilidad económica trajo como consecuencia la consolidación de la moneda nacional y la disminución de la deuda externa. Los precios petroleros en aumento de 1971 y la crisis del 1973 otorgaron entrada extra a Brasil, teniendo en cuenta que el país fue el exportador del petroleo.

\footnotetext{
${ }^{10}$ La prevalencia y aplicación más consecuente del modelo de la Escuela de Chicago tuvo lugar en Chile, durante la época del régimen de Augusto Pinochet, entre 1973 y 1989.

11 Véase más detalladamente, Souza Pires, Murilo José de - Ramos, Pedro. 2009. "O Termo Modernização Conservadora: sua Origem e Utilização no Brasil” REN (Revista Economica do Nordesta), 40. 411-425. Este enfoque y punto de vista representan las monografías recientes también. Entre ellos vale la pena mencionar a Aarão Reis, Daniel Ridenti, Marcelo - Patto Sá Motta, Rodrigo (eds.). 2014. A ditadura que mudou o Brasil. Rio de Janeiro: Jorge Zahar Editor Ltda.; Aarão Reis, Daniel. 2014. Ditadura e democracia no Brasil. Rio de Janeiro: Jorge Zahar Editor Ltda. Aarão Reis, Daniel (ed.). 2014. Ditadura e democracia.1964-2010. Rio de Janeiro.
} 
Pero a consecuencia de la política económica aplicada, el crecimiento económico no fue acompañado de la disminución de la diferencia de las rentas y desigualdades. Según Delfim Netto É preciso primeiro aumentar o 'bolo' (da renda nacional), para depois reparti-lo. En la época de la restricción de los salarios (arrocho salarial) el salario mínimo disminuyó a 15\%. En el periodo de la ocupación total, los pobres se convirtieron en más pobres.

De la población total, el 5\% más rico aumentó un 9\% su riqueza entre 1960 y 1970, y llegó a alcanzar el 36,3\% de la renta nacional. Sin embargo, la renta del $80 \%$ más pobre disminuyó un $8,7 \%$, situándose en un $36,8 \%$ en 1970 . A pesar del acelerado crecimiento económico, prevaleció y se fortaleció el proceso de empobrecimiento de los más pobres, mientras que la entrada y el consumo de las clases altas y medias aumentaron. Por eso una de las tareas más importantes del sistema democrático, ulterior a la dictadura, fue la disminución de la pobreza económica y social. El índice de Gini, que sirve para medir las diferencias sociales y de rentas, del nivel de 50,0, en 1960, aumentó a 57,0 en 1970, y a 62,0 en 1977. Sólo en 2008 alcanzó el valor de treinta y cuatro años antes.

El inicio del fin del milagro económico brasileño se vio acelerado como consecuencia de la crisis de la economía mundial de 1971 y concluyó con la crisis del petróleo de 1973.

Entre 1974 y 1979 el ritmo de crecimiento de la economía brasileña bajó, o se moderó, de $10 \%$ a 6,5\%, aumentó la inflación y el endeudamiento externo del país. Una de las causas de esto fueron los precios altos del petróleo. Aunque el país acrecentó la producción del petróleo propio, y lo exportaba también, las necesidades de la economía sobrepasaron el tamaño de la producción interna.

El crecimiento de la deuda externa anual de Brasil sobrepasó los cuatro mil millones de dólares. Al fin de la década la inflación alcanzó el 94,7\%, en 1980 subió a $110 \%$ y en 1983 a 200\%. La restitución del saldo de la deuda estatal alcanzó el 90\% de la cantidad de las entradas de la exportación. La recesión económica fue acompañada por el crecimiento del paro.

A pesar de eso, la economía y la sociedad brasileña se modernizó y cambió. Mudaron las relaciones internacionales, nacieron las democracias nuevas en América Latina también. En el subcontinente se presentaron las integraciones 
De la dictadura modernizante hasta la posdemocracía híbrida. Los cambios políticos y económicos en Brasil (1964-1985)

regionales y subregionales de nuevo tipo. Y después de la modernización conservadora se abrieron las posibilidades de desarrollo democrático.

Brasil se convirtió en miembro de los países de BRICS. Aumentó su rol en las relaciones internacionales y creció su influencia en las integraciones regionales de América Latina. Diversificó sus relaciones con los países del mundo también. A pesar de la manifestación de la crisis política del país y de la corrupción de la élite brasileña, hoy en día ya se trata de Brasil como una potencia o poder emergente que ocupa el octavo lugar en la jerarquía mundial de los países.

Aunque sabemos bien que en el caso de los países subdesarrollados casi nunca coinciden en el tiempo y el ritmo de la política con la economía y la vulnerabilidad y el desequilibrio social quedaba una de las características permanentes de estos países.

A pesar del fracaso del milagro económico brasileño, su éxito provisional y parcial contribuyó al establecimiento de la base del segundo milagro económico brasileño, iniciado en la segunda mitad de los años de 1990. Resumiendo el ensayo podemos citar las palabras de Tom Jobim: O Brasil não épara principiantes.

\section{Bibliografía}

Fico, Carlos. 2014. O golpe de 1964. Rio de Janeiro: Editora FGV.

Napolitano, Marcos. 2014. 1964. Historia do regime militar brasileiro. São Paulo: Editora Contexto.

Singer, Paul. 2014. "O processo econômico" Aarão Reis, Daniel (coord.). Modernização, Ditadura e democracia. 1964-2010. Rio de Janeiro: Fundació MAPFRE. Objetiva. 183-233.

El Ato Institucional n. ${ }^{1}$. Asequible en:

http://pt.wikipedia.org/wiki/Ato_Institucional_N\%C3\%BAmero_Um

El Ato Institucional n. ${ }^{\circ}$. Asequible en:

http://www.planalto.gov.br/ccivil_03/ait/ait-01-64.htm.

La Constitución Brasileira. Asequible en:

http://www.planalto.gov.br/ccivil_03/constituicao/constitui\%C3\%A7ao67.htm 